\title{
Diablotextron
}

\section{Ecos interseccionistas en la canción de autor}

\author{
Intersectionist echoes in singer-songwriters
}

\author{
MARÍA EsteBAN BECEDAS \\ UNIVERSIDAD NACIONAL DE EDUCACIÓN A DISTANCIA (UNED)
}

\begin{abstract}
Resumen: El interseccionismo, propuesta vanguardista que Fernando Pessoa materializó en los poemas de la serie "Chuva oblíqua", plantea una estrategia creativa basada en la superposición de planos objetivos y subjetivos. El principio del interseccionismo está presente en otras formas de literatura, como la canción de autor, ya sea con total afinidad a los poemas pessoanos (el caso de "Mundo abisal", de Jorge Drexler) o presentando cierta evolución, un estadio superior del ismo ("Nos ocupamos del mar", de Alberto Pérez, y "Debo partirme en dos", de Silvio Rodríguez). El triple carácter musical, textual y escénico de la canción permite especial dinamismo en la fragmentación del sujeto y la multiplicidad de perspectivas.
\end{abstract}

Palabras clave: Interseccionismo, Fernando Pessoa, Canción de autor, Estudios de Música Popular

Abstract: Intersectionism, an avant-garde trend reified by Fernando Pessoa in his 'Chuva Oblíqua', sets out a creative strategy based on the superimposition of objective and subjective elements. The intersectionist principle has also been put to practice in other literary genres, such as the Hispanic singer-songwriter songs, be it in total affinity with Pessoa's poems (as in Jorge Drexler's 'Mundo abisal'), or displaying some further development into a higher stage of intersectionism (Alberto Pérez's 'Nos ocupamos del mar', and Silvio Rodríguez's "Debo partirme en dos"). The coexisting musical, textual and performing dimensions inherent to songs allow for a special dynamism in the fragmentation of the subject and the presentation of multiple perspectives.

Key words: Intersectionism, Fernando Pessoa, Singer-songwriter, Popular Music Studies 


\section{Introducción}

El poeta Fernando Pessoa, principal exponente de las letras portuguesas del siglo XX, constituye además uno de los más interesantes objetos de estudio en relación al tema de la identidad, tanto desde el punto de vista de la filología y los estudios literarios como de la psicología, la psiquiatría o el esoterismo. Mediante su particular apuesta literaria, basada en la fragmentación del yo poético en numerosos heterónimos con personalidad y vivencias propias, Pessoa llega a generar toda una "galaxia" literaria de intercambios textuales y juegos de perspectivas (Tabucchi, [1990] 1997: 47). En su obsesión experimentadora con la multiplicidad, no solo aplicada al sujeto sino también a aquello que lo rodea, se erigió como creador de un movimiento estético que apenas presentó continuidad en las vanguardias europeas: el interseccionismo.

En la primavera de 1915, el autor publicó en el segundo número de la revista Orpheu (el último que llegó a editarse) una serie de seis poemas interseccionistas, nombrados mediante números romanos y agrupados bajo el título de "Chuva oblíqua" (Pessoa, [1942] 1995: 25-30), los cuales mezclan ambientes tan dispares como un puerto que se confunde con un bosque milenario, una iglesia gótica, un carrusel o la pirámide de Keops. Todos ellos comparten una característica fundamental: Presentan un paisaje que a partir de un momento bisagra confluye con otro, al que el yo poético accede mediante la contemplación o la abstracción. Abundan además los puntos suspensivos y reina cierto tono de ensoñación y angustia. El Dicionário de Fernando Pessoa e o Modernismo Português describe el interseccionismo en estos términos:

A metáfora liberta-se completamente das suas amarras, ganha asas, e permite ao poeta [...] trabalhar a aparente velocidade com que as imagens se sucedem aos nossos olhos/consciência e, num perfeito prisma de intersecções, apresentá-las já fundidas, por vezes, de um modo aparentemente não-lógico, motivando e provocando quem as lê a encontrar lugares de sentido diversificados [Cabral Martins, 2008]².

\footnotetext{
${ }^{1}$ Lluvia oblicua. Todas las traducciones del portugués que aquí figuran son propias.

2 La metáfora se libera de sus amarras, gana alas, y permite al poeta trabajar la aparente velocidad con que las imágenes se suceden ante nuestros ojos y consciencia y, en un perfecto prisma de intersecciones, presentarlas ya fundidas, en ocasiones, de un modo aparentemente ilógico, motivando y provocando a quien las lee a encontrar lugares de sentido diversificados.
} 
A modo de ejemplo, veamos este fragmento del poema I, donde se describe el momento del encuentro entre ambos planos: "E os navios passam por dentro dos troncos das árvores / Com uma horizontalidade vertical ${ }^{3}$ " ([1942] 1995: 25). Asimismo, en el poema IV, donde se intercala el dormitorio del poeta con una escena andaluza, no confluyen dos dimensiones visuales sino sonoras: "Que pandeiretas o silêncio desde quarto...!" ([1942] 1995: 28). En el poema VI, la evocación se expande en el tiempo y los espacios: "Todo o teatro é o meu quintal, a minha infancia / Está em todos os lugares"5" ([1942] 1995: $30)$.

Observamos que en ningún caso el cruce de paisajes es ajeno al yo poético, sino que parece reflejar una fragmentación interna en un sentido casi heteronímico, donde se entrecruzan los diferentes niveles de un yo en permanente dispersión [Cabral Martins, 2008]. El encuentro parece tener lugar dentro de sí mismo al tiempo que ante sus ojos, como se describe en los últimos versos del ya citado poema I: "Esta paisagem toda [...] chega ao pé de mim, e entra por mim dentro, / E passa para o outro lado da minha alma... ${ }^{\prime \prime}$. En este sentido, el caso más extremo lo hallamos en el poema III ([1942] 1995: 27), donde el trazo en el papel termina por enterrar al poeta bajo la pirámide de Keops, en una identificación del acto de escribir con el paisaje imaginado. En el poema V ([1942] 1995: 29), asistimos por primera vez a la ruptura de la ensoñación y el regreso del yo poético al plano presentado como objetivo:

\footnotetext{
De repente alguém sacode esta hora dupla como numa peneira

E, misturado, o pó das duas realidades cai

Sobre as minhas mãos cheias de desenhos de portos ${ }^{7}$
}

Cuando, en el poema I, se afirma "Naõ sei quem me sonho" ([1942] 1995: 25), una discordancia gramatical retrata la dicotomía interna; en el III, la intersección traza dentro del poeta una línea visual que funciona como una

\footnotetext{
${ }^{3}$ Y los navíos pasan por dentro de los troncos de los árboles / Con una horizontalidad vertical.

${ }^{4}$ ¡Qué panderetas el silencio de este cuarto...!

5 Todo el teatro es mi quintal, mi infancia / Está en todos los lugares.

${ }^{6}$ Todo este paisaje [...] llega hasta mis pies, y entra dentro de mí / Y pasa hasta el otro lado de mi alma...

7 De repente, alguien sacude esta hora doble como en un tamiz / Y, mezclado, el polvo de las dos realidades cae / Sobre mis manos llenas de dibujos de puertos.

${ }^{8}$ No sé quién me sueño.
} 
frontera entre el yo ontológico y el sujeto pensante: "E uma alegria de barcos embandeirados erra / Numa diagonal difusa / Entre mim e o que eu penso...9" ([1942] 1995: 27). Podemos afirmar entonces que el autor se vale de la técnica interseccionista para indagar en su compleja relación con el yo, en la misma línea que el desdoblamiento heteronímico, si bien estos poemas se desarrollan a partir de un único sujeto y además aparecen firmados por Fernando Pessoa ortónimo.

Aunque los poemas de "Chuva oblíqua"10 constituyen el testimonio más representativo (y prácticamente único) de interseccionismo consciente 0 voluntario [Zenith, 2021: 442], la que podríamos denominar "técnica interseccionista”, un cruce de planos acentuado como eje vertebrador del texto, está presente de manera instintiva en diversas formas de literatura; al fin y al cabo, la idea del enlace de dimensiones o el acceso a nuevos paisajes mentales o tangibles, objetivos o subjetivos, a través del flujo de conciencia representa un tema universal, además de resultar eficaz como estrategia creativa. Zenith señala, de hecho, que el concepto del interseccionismo fue diluyéndose en la teorización de Pessoa hasta llegar a significar "casi cualquier tipo de escritura que no fuera lineal o a una sola voz" [2021: 430]. Tomaremos por tanto el interseccionismo, en su sentido amplio, como herramienta metodológica para trabajar una técnica creativa que tiene lugar en una de las formas de lírica menos exploradas dentro de los estudios filológicos: la canción de autor. Como género literario diferenciado de la poesía pero definido precisamente por la búsqueda de "poeticidad" (Marc Martínez, 2011: 55), la canción de autor representa uno de los lenguajes donde mejor florecen los juegos poliédricos, ya que en ella confluyen, al menos, tres dimensiones: la musical, la textual y la escénica (Marc Martínez, 2011: 53). Esta característica permite, con mayor dinamismo que en la poesía escrita, variar la perspectiva del enunciador e incluso de los receptores al tiempo que se experimenta con el lenguaje, a menudo con cierto afán lúdico.

\footnotetext{
${ }^{9}$ Y una alegría de barcos con banderas vaga / En una diagonal difusa / Entre mí y lo que yo pienso...

${ }_{10}$ Los seis poemas se encuentran disponibles en línea, conservando la ortografía original, en http://arquivopessoa.net/textos/835 [Fecha de consulta: 12 de septiembre de 2021].
} 
Cabe señalar que, en el campo de los estudios filológicos, aún escasean los trabajos de investigación que aborden letras de canciones desde el punto de vista textual, si bien son habituales los estudios sobre las relaciones entre literatura y música (Alonso, 2002; Laín Corona, 2018; Viñas Piquer, 2020; Noguerol, 2021) o reflexiones sobre la construcción del personaje de autor en cantautores con proyección internacional (Romano, 2021). Con objeto de aportar nuevas perspectivas en el estudio de esa forma de lírica tan inexplorada como sustancial, en este trabajo se plantean tres casos concretos: "Mundo abisal", de Jorge Drexler (Drexler, 2010); "Nos ocupamos del mar", de Alberto Pérez, miembro constituyente junto a Joaquín Sabina y Javier Krahe del grupo La Mandrágora (Pérez, 1981); y "Debo partirme en dos", de Silvio Rodríguez (Rodríguez, 1978a). El orden cronológico en que se presentan (inverso, en este caso) es indiferente; veremos que se trata de textos configurados de un modo similar a los poemas de "Chuva oblíqua", que establecen cierta relación de gradación en cuanto a su cercanía a la propuesta pessoana, y se valen de la técnica interseccionista para lograr, como veremos, un propósito acorde con su condición de textos cantables. Así pues, considerando que, en el lenguaje de la canción, la forma y el contenido son igualmente relevantes [Marc Martínez, 2011: 57], realizaremos un breve comentario métrico y semántico ${ }^{11}$ de cada letra, además de analizar los rasgos interseccionistas que relacionan estas tres canciones ${ }^{12}$. Trataremos de discernir en cada una los diferentes planos de intersección y cómo se desenvuelve el cruce, para más adelante plantear una propuesta de categorización y extraer una serie de conclusiones.

\footnotetext{
${ }^{11}$ Por las limitaciones de espacio resulta imposible abordar en este trabajo el análisis musical y escénico, de modo que nos referiremos a esos aspectos solo de forma somera.

${ }^{12}$ Los anexos 1, 2 y 3 presentan las letras completas, a partir de su transcripción sonora. Como propuesta gráfica, optamos por iniciar cada verso en mayúscula y no añadir signos de puntuación a final de verso, a excepción del punto final, la coma del vocativo y en determinados casos puntos suspensivos, dado que en las canciones cada línea constituye una unidad independiente y la sintaxis global es a menudo subjetiva. En la canción de Silvio Rodríguez (Anexo 3), empleamos comillas para marcar la autocita irónica y cursivas cuando se alude directamente a otros títulos de su discografía, para una mejor comprensión de la estructura del texto.
} 


\section{Análisis de tres canciones}

\section{Mundo abisal}

Nuestra primera canción muestra una estructura compleja y se caracteriza por la irregularidad métrica, así como por la disparidad de las rimas. Se compone de seis elementos: una primera estrofa de seis versos que funciona también de colofón; una segunda estrofa de cuatro; un estribillo constituido por tres etapas de tres versos cada una que a su vez vienen introducidas por el verso "Inmersión, inmersión"; un puente aislado de tres versos, al final del estribillo; una tercera estrofa de cuatro versos, a la manera de la segunda; y finalmente la repetición de la primera estrofa. Todas las estrofas cierran con el sintagma "mundo abisal", que da título a la canción y marca la única rima recurrente.

Así, en la primera de ellas, la voz nos ofrece el paisaje de un dormitorio en penumbra. Inmediatamente, la imagen de una mujer que entra en dirección a la cama se convierte en la bisagra que transforma el cuarto en el fondo marino. Es la falta de luz lo que permite establecer esa relación entre los dos mundos. De esta manera, los tres primeros versos ("Ella entra / Cierra la puerta tras de sí / Y cruza el cuarto en diagonal") representan el primer plano; los tres siguientes, el segundo ("Parten dos escafandristas / En la penumbra / Rumbo al mundo abisal"). En la segunda estrofa, ambos planos ya han confluido y el autor describe el brillo de la piel amante, relacionándolo con las fosforescencias del fondo marino, y su lentitud de movimientos: en el mar, por la resistencia del agua; en el dormitorio, por delicadeza. El empleo de una metáfora celeste ("Va dejando una estela de aurora boreal") parece una pequeña incursión en un tercer plano.

En el estribillo prosiguen las metáforas que permiten mantener el paralelismo constante entre los paisajes: "Cerremos las compuertas" se aplica al dormitorio y a un posible submarino, de la misma manera que "las inciertas profundidades" aluden al fondo del mar al tiempo que al encuentro sexual. La paradoja presente en "Bajar y bajar hacia las alturas" nos sitúa en un ambiente casi místico. Al final de la tercera etapa del estribillo y el puente, encontramos un grupo de versos con estudiados mecanismos de cohesión interna: 


\begin{tabular}{|c|c|l|}
\hline \multirow{2}{*}{$\begin{array}{c}\text { Estribillo } \\
\text { (3ª etapa) }\end{array}$} & Donde & apenas dura la luz del día \\
\cline { 2 - 3 } & \multicolumn{2}{|c|}{ Las ganas tuyas, las ganas mías } \\
\hline \multirow{2}{*}{ Puente } & La daga & fría apretada entre los dientes \\
\cline { 2 - 3 } & La draga & clarividente de la melancolía \\
\cline { 2 - 3 } & &
\end{tabular}

Al paralelismo anafórico de los dos primeros versos ("Donde [...] / Donde [...]") se suma la antítesis entre las nociones de luz y oscuridad, que viene además vinculada al concepto de "algarabía", al contrario de lo que suele asociarse a ella: la quietud. En la fórmula distributiva "Las ganas tuyas, las ganas mías" encontramos el único testimonio de primera persona del singular, lo cual es predominante en los poemas de Pessoa. Más adelante, una paronomasia contrapone la imagen de la "daga" (que, como veremos, encuentra continuidad en la estrofa siguiente) y la "draga", una herramienta de excavación en el fondo marino, que en este caso se identifica con el sentimiento de melancolía: oscuro, profundo, insondable. En la tercera y última estrofa, Drexler termina de sumergirnos en el segundo paisaje. Manteniendo las alusiones a lo lumínico, se refiere a los peces monstruosos (y "resplandecientes") que habitan el fondo marino, como expresión de su misterio y su peligro. Repite aquí la palabra "dientes", que remite a la ya mencionada imagen de la daga y permite tres rimas consecutivas. La repetición de la primera estrofa al final de la canción nos devuelve a la calma del dormitorio, logrando un efecto cuasi especular.

En cuanto a la melodía, los momentos más frenéticos musicalmente y la mayor rapidez enunciativa ilustran la escena submarina, mientras que los dos extremos de la canción, correspondientes a la atmósfera intimista, conllevan motivos más pausados. Dado que en los primeros segundos se evoca, a través de sonidos agudos, el misterio de "las inciertas profundidades", podría afirmarse que el segundo plano preexiste en la canción antes de la entrada de la letra. 
Observamos que se trata de un texto construido de manera muy similar a los poemas de "Chuva oblíqua": dos planos en principio inconciliables (en este caso, el dormitorio y el fondo del mar) conviven aquí, de la manera en que se entrelazaban el bosque y el puerto en el poema I, o la fiesta con el silencio del cuarto en el poema IV. En "Mundo abisal" se establece el juego de perspectivas con lo visual, lo sensitivo, siempre desde el yo, aunque el elemento bisagra sea la figura externa de una mujer. Como ya señalamos, el yo poético solo se implica en el texto desde la primera persona del plural ("aventurémonos", "dejando que el vértigo nos acaricie"), como parte de la pareja amante.

\section{Nos ocupamos del mar}

A primera vista se aprecia que la canción de Alberto Pérez tiene estructura simétrica y cómputo silábico regular, lo que parece revelar una apuesta estética ${ }^{13}$. También en este caso contamos con tres estrofas, compuestas por cinco octosílabos que riman en consonante, a los que se añade un inciso tetrasílabo en el tercer verso (doce sílabas en total), que a su vez rima con este y en la enunciación del texto aparece entre pausas marcadas ${ }^{14}$. Es decir, el esquema rítmico de las estrofas es el siguiente:

\begin{tabular}{|c|c|}
\hline Estrofa 1 & 8a 8a 12b (8b+4b) 8a 8b \\
\hline Estrofa 2 & 8c 8c 12d (8d+4d) 8c 8d \\
\hline Estrofa 3 & $8 e$ ee 12f $(8 f+4 f) 8 e 8 f$ \\
\hline
\end{tabular}

El estribillo aparece asimismo tres veces y consta de dos partes muy diferenciadas, la primera de cuatro versos (impares blancos, pares con rima consonante) y la segunda de tres (el primer verso es blanco pero contiene una rima interna con los dos monorrimos siguientes). Así, el esquema rítmico varía

\footnotetext{
${ }^{13}$ Para mantener el cómputo silábico, Pérez recurre a diversas estrategias, como la apócope del adverbio "donde" en la segunda estrofa: "Do quien no compra perece", que añade a la letra un matiz popular e incluso arcaizante; o la adhesión de una conjunción copulativa en el último verso de la canción: "Y mi voz en su costado", que no había sido necesaria en los estribillos anteriores porque siempre se empleaban elementos bisílabos ("mis ojos", "mis manos").

${ }^{14}$ En la transcripción del texto estos incisos figuran separados por una coma.
} 
notablemente, tanto en las dos partes del estribillo como con respecto a las estrofas, si bien la base continúa siendo octosilábica:

\begin{tabular}{|c|c|c|}
\hline \multirow{2}{*}{ Estribillo 1 } & Primera parte & $8_{-} 12 \mathrm{a} 8 \_8 \mathrm{a}$ \\
\cline { 2 - 3 } & Segunda parte & $11_{-}\left(3 \mathrm{~b}+8_{-}\right) 8 \mathrm{~b} 8 \mathrm{~b}$ \\
\hline \multirow{2}{*}{ Estribillo 2 } & Primera parte & $8_{-} 12 \mathrm{c} 8 \_8 \mathrm{c}$ \\
\cline { 2 - 3 } & Segunda parte & $11_{-}\left(3 \mathrm{~b}+8_{-}\right) 8 \mathrm{~b} 8 \mathrm{~b}$ \\
\hline Estribillo 3 & Primera parte & $8_{-} 12 \mathrm{~d} 8 \_8 \mathrm{~d}$ \\
\cline { 2 - 3 } & Segunda parte & $11_{-}\left(3 \mathrm{~b}+8_{-}\right) 8 \mathrm{~b} 8 \mathrm{~b}$ \\
\hline
\end{tabular}

La primera parte del estribillo cambia el contenido cada vez; la única frase repetida a lo largo de la canción está en los dos primeros versos de la segunda parte: "Es cansado, por eso al llegar la noche / Ella descansa a mi lado". En el tercer y último verso de la segunda parte, varía el atributo humano mencionado ("mis ojos”, "mis manos", “mi voz"), en un paralelismo sintáctico con la oración anterior, con la que comparte el verbo "descansar". Encontramos que la palabra elegida siempre se relaciona con lo expresado en la primera parte: En el primer estribillo, se emplean los verbos "cuidar" y "vigilar", con lo que luego aparecen los ojos; en el segundo, se alude al trabajo de la tierra, de modo que lo que descansan son las manos; en el tercero se recurre a elementos inmateriales, y por eso se menciona la voz. Cabe señalar además que en todos los casos aparecen contrapuestas dos expresiones con connotaciones diferentes, una positiva y otra levemente negativa, las primeras aplicadas a ella y las segundas a él, al yo poético. En el primer estribillo, se trata de los ya señalados "cuidar" y "vigilar"; en el segundo, se enumeran elementos visibles ("troncos, frutos y flores") frente a "lo escondido", que aporta matiz positivo de misterio; en el tercero y último, la diferencia es más sutil y subjetiva, y sin embargo apreciable, un hallazgo poético: "Yo lo que tiene importancia / Ella todo lo importante".

En esta letra, el primer plano de intersección no está completamente definido y parece menos relevante que el segundo; puede tratarse de un concierto o una escucha en diferido, pero es en cualquier caso un contexto donde el yo poético se dirige a un auditorio. Al contrario que en el texto de Drexler, aquí la voz cantante previene a quien escucha de que va a producirse 
un cambio, un cruce, y es precisamente ese aviso lo que funciona como elemento bisagra: "Y coloco aquí un mensaje". Se produce entonces un cambio drástico de melodía, con la llegada del estribillo, y el texto da lugar a una canción de amor bajo la apariencia de un mensaje ecologista, que es lo que sugiere el título: "Nos ocupamos del mar". Así, el estribillo coincide plenamente con el segundo plano de intersección. Observamos que, en la primera parte de este, predomina el campo semántico de la naturaleza, marítima y terrestre; en la segunda se describe posición en que los amantes reposan en la cama, mirando hacia el mismo lado. Nos encontramos pues con un caso de doble intersección de planos; el primero en relación a las estrofas y el estribillo, y afecta por tanto a la canción completa; el segundo tiene lugar dentro del propio estribillo y, más en la línea de la canción anterior, consiste en un cambio de paisaje visual donde la bisagra es un elemento del cuerpo humano (según corresponda, ojos, manos o voz).

En definitiva, no se trata de un texto donde confluyen dos dimensiones reales o subjetivas; son dos canciones en una, también a nivel musical. En las estrofas, el sonido característico de la Mandrágora, que recuerda a Georges Brassens y a las chirigotas gaditanas por el uso del kazoo, deja paso a una melodía de balada en el segundo plano. Cabe señalar además que, en las estrofas, la voz hace repetidas críticas a los engaños de la publicidad ("Ya que no fue comercial / Y es cosa que se agradece"; "Raro es que la verdad / Mediante publicidad / Alguna vez se abra paso"), lo que refuerza el tinte jocoso que caracteriza al primer plano de la canción; en el segundo plano, por el contrario, el tono es en todo momento de ternura, aunque bastante alejado del melodrama tradicionalmente atribuido a las baladas o la música de cantautor.

En este caso, la gran diferencia respecto a "Chuva oblíqua" radica en que el yo poético hace partícipe al oyente del efecto interseccionista. De hecho, la ilusión de presencia de un auditorio es lo que da sentido al cruce de planos; el imaginado público cumple la función de la penumbra del dormitorio en la canción de Drexler. Por último, es necesario señalar que, aunque una vez más el juego versa sobre dos amantes, en este caso se mantiene la perspectiva del yo en primera persona del singular, frente a la tendencia del texto anterior. 


\section{Debo partirme en dos}

El título de la canción revela desde el principio que en ella se plantea un conflicto de dualidad y que el claro protagonista es el sujeto, el yo poético, al contrario que en los dos casos anteriores. Veremos que nos encontramos ante una letra muy sofisticada, un nuevo caso de interseccionismo radical y consciente, con una finalidad clara de denuncia política sin renunciar al humor. En ella están presentes tres tipos de elementos: La estrofa de cuatro versos, un falso estribillo autoparódico y el que podríamos considerar el estribillo serio o real, que viene siempre introducido por la frase que da título a la canción, "Debo partirme en dos", la cual se pronuncia dos veces. El estribillo paródico se compone de cuatro versos donde riman en asonante los pares; el estribillo real, de seis versos, donde los dos primeros se repiten rimando en asonante y el tercero y el sexto presentan un paralelismo: "Y no importa la suerte que pueda correr una canción / [...] / Y no importa que luego me suspendan la función". En estos versos, con una referencia directa a la censura, la rima es consonante. Dentro de cada verso repetido (vv. 1-2 y 4-5) existe un paralelismo distributivo que además incluye rimas asonantes internas: "Unos dicen que allí, otros dicen que allá / Y solo quiero decir, solo quiero cantar". Observemos que el verbo "decir" aparece sin complemento argumental, lo que refuerza su potencia y le otorga un matiz de verdad, de denuncia. Cada tipo de estribillo aparece tres veces, alternado con las seis estrofas, como muestra la siguiente tabla:

\begin{tabular}{|c|c|}
\hline Estrofa 1 (4 vv.) & Rima consonante $\mathrm{a} \mathrm{a} \mathrm{b} \mathrm{b}$ \\
\hline Falso estribillo (4 vv.) & Rima asonante _ $\mathrm{c}_{-} \mathrm{c}$ \\
\hline Estrofa 2 (4 vv.) & Rima asonante _ $d_{-} d$ \\
\hline \multicolumn{2}{|c|}{ "Debo partirme en dos..." } \\
\hline Estribillo (6 vv.) & e e (asonante) f e e f (consonante) \\
\hline Estrofa 3 (4 vv.) & $\begin{array}{l}\mathrm{g} \mathrm{g} \text { (consonante) } \mathrm{h} \mathrm{h} \text { (consonante, } \\
\text { rimando singular y plural) }\end{array}$ \\
\hline Falso estribillo (4 vv.) & Rima asonante _ ${ }_{-}{ }^{c}$ \\
\hline Estrofa 4 (4 vv.) & Rima asonante i i j j \\
\hline
\end{tabular}




\begin{tabular}{|c|c|}
\hline Estribillo (6 vv.) & e e (asonante) f e e f (consonante) \\
\hline Estrofa 5 (4 vv.) & $\begin{array}{c}\mathrm{k} \mathrm{k} \text { (consonante) I I (consonante, rimando } \\
\text { plural y singular) }\end{array}$ \\
\hline Falso estribillo (4 vv.) & Rima asonante _ ${ }_{-}{ }^{\mathrm{c}}$ \\
\hline Estrofa 6 (4 vv.) & $\mathrm{m} \mathrm{m} \mathrm{(consonante)} \mathrm{n} \mathrm{n} \mathrm{(asonante)}$ \\
\hline \multicolumn{2}{|c|}{ "Debo partirme en dos..." } \\
\hline Estribillo (6 vv.) & e e (asonante) f e e f (consonante) \\
\hline
\end{tabular}

En cuanto a las estrofas, la primera consiste en una suerte de CAPTATIO BENEVOLENTIAE, donde el yo poético asegura haber recibido críticas por sus textos ("Hace tiempo que vengo lidiando con gentes / Que dicen que yo canto cosas indecentes") y nos previene de un desastre lírico inminente que tendrá lugar dentro de su canción. De esta manera se introduce el que hemos denominado "falso estribillo", el cual imita el esquema de las canciones pop, tanto en el contenido como en lo musical, y exagera su simpleza: "Te quiero, mi amor / No me dejes solo / No puedo estar sin ti / Mira que yo lloro".

Se percibe además un cambio en la voz del cantante, que se vuelve más aguda, así como un silabeo más pronunciado. Esto se hace especialmente evidente en el último falso estribillo, donde la burla se suma al aparente hartazgo del intérprete por la repetición de esos versos vacíos.

En la segunda estrofa tiene lugar una apelación directa al público, lo que supone un paso más con respecto a la canción de Alberto Pérez: Si en la primera estrofa nos encontrábamos con la demanda de "Que nadie se levante"; en esta, la interpelación es constante, con la pregunta retórica "¿No ven?" y a continuación tres versos constituidos por una oración imperativa: "Que el público se agrupe y que me aclame / Que se acerquen los niños, los amantes del ritmo / Que se queden sentados los intelectuales". Con este recurso, en ambas canciones se logra una apariencia de simultaneidad en el tiempo. Sin embargo, en "Nos ocupamos del mar", la rima consonante y la rigidez de la estructura iban en consonancia con el carácter lúdico de la letra; en este caso, la falta de rima y la disparidad en los esquemas métricos refuerzan el efecto de discurso improvisado, dirigido expresamente al público al que apela. 
En los cuatro versos de la tercera estrofa encontramos una insistente anáfora: "Yo también [...] / Yo también [...] / Yo también [...] / Yo también [...]", análoga con la repetición en el estribillo no paródico de la conjunción copulativa, que introduce los versos 1, 2, 4 y 5, aportando un matiz iterativo: "Y solo quiero decir [...] / Y no importa [...]". El tono de esta estrofa es concesivo, un reconocimiento por parte de la voz de las debilidades de su propia trayectoria musical y, como ocurría en la primera, sirve para introducir el falso estribillo.

La cuarta estrofa es explicativa; en ella el cantautor parece establecer una distinción entre las canciones ligeras, inocentes, y las que él escribe y le han resultado problemáticas, por hablar de "cosas de este mundo". Contiene varios elementos autorreferenciales: En primer lugar, la cita explícita de dos canciones de su autoría que han conocido el éxito y adquirido especial valor simbólico, "Fusil contra fusil" ([1968] 2006) y "La era [está] pariendo [un corazón]" (1978b), que aparece con el título abreviado. Menciona también el movimiento donde se integra su producción cultural, la denominada "nueva trova" cubana.

En la quinta estrofa, el autor reconoce que preferiría cantar de incógnito ("encapuchado") para pasar desapercibido entre su público, aunque ello supusiera renunciar al éxito social. Se trata de una nueva declaración de intenciones de su poética; la prioridad es cantar su verdad, como se recalca una y otra vez en el estribillo. Cabe señalar que la rima se distribuye en la quinta estrofa como en la tercera, con pareados consonantes aunque rimando singular y plural: "santo" con "cantos" y "citas" con "bonita". El estribillo paródico que sigue presenta una anomalía, pues viene introducido por la conjunción adversativa "Pero". En la sexta estrofa, para terminar, la voz del autor asegura no querer repetir ese estribillo embarazoso y expresa su vergüenza y arrepentimiento, como si la canción efectivamente sucediera en tiempo real. El último estribillo cierra de manera contundente añadiendo un posesivo: "Mi función".

En cuanto a los planos de intersección, un recital con público en directo representa el primero, por las numerosas interpelaciones que ya señalamos $y$ 
referencias visuales de los asistentes: "Algunos ojos miran con mal brillo", encontramos en la sexta estrofa. Así, la primera tentación sería pensar que el estribillo paródico constituye el segundo plano; sin embargo, este aún forma parte del primer plano y es la enunciación de la frase "Debo partirme en dos" lo que funciona como elemento bisagra. Con ella accedemos a una segunda dimensión donde la voz habla libremente al mismo auditorio, en el que hemos denominado estribillo serio. De este modo, los dos planos que coexisten son en realidad una situación de censura y otra de libertad expresiva, que trasciende el texto. La voz del yo poético se mueve libremente entre ambos planos, a través del juego de estrofas y estribillos, convirtiendo esta canción interseccionista en la más alejada del concepto pessoano de las tres marcadas aquí. Ese movimiento entre planos, que no tiene lugar en los poemas de "Chuva oblíqua", representa en última instancia un triunfo de la libertad anhelada.

\section{Comentario conjunto}

Nos encontramos ante tres operaciones textuales donde la técnica interseccionista tiene diferente alcance e implicaciones, orientada hacia una finalidad precisa en cada caso. Si los poemas pessoanos retrataban escenas confluyentes con protagonismo del instante, la canción de Drexler es fundamentalmente descriptiva y atañe a un paisaje visual, aunque con cierta tentación sinestésica; la de Pérez cuenta con una leve progresión narrativa en sus dos planos; la de Rodríguez reproduce un flujo de conciencia y, como ya hemos señalado, apariencia de oralidad simultánea, cualidad que comparte con "Nos ocupamos del mar". Mientras que en "Chuva oblíqua" confluyen planos del objeto con la percepción, de lo físico con lo psíquico, del espacio con el tiempo y la idea (Cabral Martins, 2008), en la primera canción el cruce pertenece a lo visual y a sutiles percepciones táctiles; en los otros dos casos, a lo sonoro, dado que las dimensiones contrapuestas son discursos orales. Cabe señalar además que el tono varía respecto a la congoja pessoana, dejando lugar en estas canciones a la celebración, el humor y la denuncia. Así, como propuesta de categorización, podemos establecer una gradación atendiendo a 
su cercanía a la propuesta pessoana y a la función del yo poético dentro del texto.

Respecto a lo primero, la canción de Jorge Drexler es la más afín estéticamente a los poemas de "Chuva oblíqua", seguida de la de Alberto Pérez, considerando que también en ella existe un contraste de elementos visuales, orientado a una sutil crítica a la trivialidad del lenguaje publicitario; y por último la de Silvio Rodríguez, donde la intersección se produce entre meras abstracciones. En cuanto a lo segundo, la gradación sería a la inversa, dado que "Debo partirme en dos" representa la máxima expresión del yo, que es el punto de partida en "Chuva oblíqua"; en "Nos ocupamos del mar" tienen idéntica relevancia el yo poético y el auditorio dentro del fenómeno interseccionista y se dan sentido mutuamente; en "Mundo abisal", el cruce de planos nace de elementos externos a la voz del poeta. En este sentido, resulta significativo que Pérez y Rodríguez anticipen la intersección en su canción, mientras que Drexler la introduce de forma abrupta. Así pues, podemos afirmar que en "Mundo abisal" predomina la tercera persona; "Nos ocupamos del mar" se focaliza en la segunda; y, en "Debo partirme en dos", además de un "yo" del que emana el discurso y un constante "vosotros" a los que se interpela, subyacen unos terceros indefinidos, la autoridad con la que se produce un conflicto, un régimen censor. Esta canción trata el tema de la complejidad de los textos con respecto al tipo de receptor, el reclamo de lo comercial frente a los principios del cantautor y su compromiso con el arte (Carrera Pérez, 2019: 285), las contradicciones del intelectual dentro de su contexto histórico, y es, por tanto, la que más abunda en la cuestión de la dicotomía identitaria de las tres presentadas aquí.

\section{Conclusiones}

Parece claro que, frente a la introspección tradicionalmente asociada a la poesía escrita, la canción es un texto proyectado hacia fuera, que busca puntos de encuentro con el oyente en su afán de provocar una emoción, si no colectiva, compartida. Esto se ve reflejado en la manera en que los tres textos aquí trabajados aplican la técnica interseccionista, la cual resulta útil como 
herramienta metodológica para abordar esta maniobra textual. Jorge Drexler nos hace partícipes de una escena a la que también él asiste como espectador.

En las letras de Alberto Pérez y Silvio Rodríguez, la bisagra que nos traslada al segundo plano es precisamente el aviso de que la intersección va a producirse, lo cual solo tiene lugar en un texto concebido para ser interpretado. En estas canciones convive el yo poético con un receptor indeterminado, equivalente al "lector ideal", que funciona como eje transformador del propio texto. Así, el uso de la técnica interseccionista no está íntimamente vinculado con la noción de las identidades múltiples, como sucede en Pessoa, sino que representa una original estrategia creativa, el juego de una supuesta retroalimentación emisor-receptor, cantautor-auditorio, que permite a su vez reflejar dicotomías internas ("Debo partirme en dos") o acoplar elementos en apariencia inconciliables ("Nos ocupamos del mar").

Por otro lado, aunque es cuestionable que estos tres autores hallasen inspiración directa en Pessoa, sí podemos afirmar que tuvieron una intuición compartida con uno de los más cautivadores autores europeos, y con ello asegurar la existencia de ciertos universales poéticos al que tanto los autores de literatura escrita como los escritores de canciones tienen acceso. En última instancia, el uso de sofisticados recursos literarios como los aquí descritos en la construcción de las letras refuerza el argumento de que la canción de autor es literatura y como tal debe ser abordada, así como determinados autores de canciones merecen ser considerados entre los grandes de nuestras Letras.

\section{Bibliografía}

Alonso, Silvia et al. (2002). Música y literatura: Estudios comparativos y semiológicos. Madrid: Arco Libros.

Cabral Martins, Fernando (2008). Dicionário de Fernando Pessoa e do Modernismo Português. Lisboa: Caminho.

Carrera Pérez, Leticia (2019). Silvio Rodríguez: Contra la cristalización del gusto y de las ideas. Elias J. Feijó Torres. Santiago de Compostela: Universidade de Santiago de Compostela.

LAín Corona, Guillermo et al. (2018). Joaquín Sabina o fusilar al rey de los poetas. Madrid: Visor Libros.

MARC MARTíneZ, Isabelle (2011). "De la poésie avant toute chose: Pour une approche textuelle des musiques amplifiées", Synergies Espagne, n.ำ 4, 
pp. 51-61.

Noguerol, Francisca et al. (2021). Entre versos y notas: Canción de autor en español. Kassel: Reichenberger.

PessoA, Fernando [1942] (1995). "Chuva oblíqua". En João Gaspar Simões y Luiz de Montalvor (eds.), Poesias. Lisboa: Ática, pp. 25-30.

Romano, MARCEla (2021). "Presencias y figuras: Acerca de dos «complementarios»". En Marcela Romano, María Clara Lucifora y Sabrina Riva (eds.), Un antiguo don de fluir: La canción, entre la música y la literatura. Mar del Plata: EUDEM, pp. 195-215.

TABUCCHI, Antonio [1990] (1997). Un baúl lleno de gente: Escritos sobre Pessoa. Pedro Luis Ladrón de Guevara Mellado. Madrid: Huerga y Fierro, La Rama Dorada.

VIÑAS PIQUER, David (2020). "Presencia de la poesía en la canción de autor: El efecto Dylan", Tropelías: Revista de Teoría de la Literatura y Literatura Comparada, n. 7, pp. 727-745.

ZenITH, Richard (2021). Pessoa: A biography. Nueva York: Liveright Publishing.

\section{Discografía}

DREXLER, Jorge (2010). "Mundo abisal". En Amar la trama, Warner Music Spain. PÉREZ, Alberto (1981). "Nos ocupamos del mar". En La mandrágora, Sony Music.

RODRíGUEZ, Silvio [1968] (2006). "Fusil contra fusil”. En Érase que se era, vol. 2, SGAE.

RODRíGuEZ, Silvio (1978a): "Debo partirme en dos". En Al final de este viaje..., SGAE.

RODRíGUEZ, Silvio (1978b): "La era está pariendo un corazón". En Al final de este viaje..., SGAE.

Fecha de recepción: 26 de agosto de 2021

Fecha de aceptación: 02 de diciembre de 2021 